\title{
Adverse childhood experiences and adult cardiometabolic risk factors and disease outcomes: Cross-sectional, population- based study of adults in rural Uganda
}

\author{
Andrew Wooyoung Kim ${ }^{1,2}$, Bernard Kakuhikire ${ }^{3}$, \\ Charles Baguma ${ }^{3}$, Crystal M North ${ }^{2,4,5,6}$, \\ Emily N Satinsky², Jessica M Perkins ${ }^{7}$, \\ Patience Ayebare ${ }^{3}$, Allen Kiconco ${ }^{3}$, \\ Elizabeth B Namara ${ }^{3}$, David R Bangsberg,8, \\ Mark J Siedner $2,5,6,9$, Alexander C Tsai $2,3,5,6$
}

\author{
'SAMRC/Wits Developmental Pathways for Health Research Unit, \\ Faculty of Health Sciences, University of the Witwatersrand, \\ Johannesburg, South Africa \\ ${ }^{2}$ Center for Global Health, Massachusetts General Hospital, \\ Boston, Massachusetts, USA \\ ${ }^{3}$ Mbarara University of Science and Technology, Mbarara, \\ Uganda \\ ${ }^{4}$ Division of Pulmonary and Critical Care, Massachusetts General \\ Hospital, Boston, Massachusetts, USA \\ ${ }^{5}$ Mongan Institute, Massachusetts General Hospital, Boston, \\ Massachusetts, USA \\ ${ }^{6}$ Harvard Medical School, Boston, Massachusetts, USA \\ ${ }^{7}$ Peabody College, Vanderbilt University, Nashville, Tennessee, \\ USA \\ ${ }^{8}$ Oregon Health and Science University - Portland State \\ University School of Public Health, Portland, Oregon, USA \\ ${ }^{9}$ Medical Practice Evaluation Center and Division of Infectious \\ Diseases, Massachusetts General Hospital, Boston, MA, USA
}

\section{Correspondence to:}

Andrew Wooyoung Kim, PhD

SAMRC/Wits Developmental Pathways for Health Research Unit Faculty of Health Sciences

University of the Witwatersrand

29 Princess of Wales Terrace, Parktown

Johannesburg

South Africa

2193

awkim@mgh.harvard.edu
Background Cardiovascular diseases (CVD) pose a major threat to public health in sub-Saharan African communities, where the burden of these classes of illnesses is expected to double by 2030. Growing research suggests that past developmental experiences and early life conditions may also elevate CVD risk throughout the life course. Greater childhood stress and adversity are consistently associated with a range of adult CVDs and associated risk factors, yet little research exists on the long-term effects of early life stress on adult physical health outcomes, especially CVD risk, in sub-Saharan African contexts. This study aims to evaluate the associations between adverse childhood experiences and adult cardiometabolic risk factors and health outcomes in a population-based study of adults living in Mbarara, a rural region of southwestern Uganda.

Methods Data come from an ongoing, whole-population social network cohort study of adults living in the eight villages of Nyakabare Parish, Mbarara. A modified version of the Adverse Childhood Experiences-International Questionnaire (ACEs) assessed past exposure to physical, emotional, and sexual adversity. Participants also took part in a health fair where medical histories on cardiometabolic risk factors and cardiovascular diseases were gathered. Multiple logistic regression models estimated the associations between ACEs and cardiometabolic risk factors and health outcomes.

Results Data were available on 545 adults. The average number of ACEs was 4.9 out of a possible 16. The cumulative number of ACEs were associated with having a history of heart attack and/or heart failure (adjusted odds ratio $(\mathrm{AOR})=1.11,95 \%$ confidence interval $(\mathrm{CI})=0.999-1.234, P=0.051)$, but the estimated association was not statistically significant. ACEs did not have statistically significant associations with any others measures of adult cardiometabolic risk and CVD. 
Conclusions Adverse childhood experiences are not associated with a range of adult cardiometabolic risk factors and health outcomes in this sample of rural Ugandan adults. Further research in this sample is necessary to identify the pathways that may motivate these null relationship and possibly protect against adverse cardiometabolic and cardiovascular health outcomes.

Cardiovascular diseases (CVDs) are the leading cause of mortality globally, accounting for approximately 17.8 million deaths per year [1]. Increasing trajectories of CVD are especially concerning in sub-Saharan Africa, a region already facing a double burden of disease from non-communicable diseases (NCDs) and infectious diseases [2] and where the burden of CVD is expected to double by 2030 [3]. While dietary and lifestyle factors account for a major portion of overall CVD mortality and morbidity, growing research suggests that past developmental experiences and early life conditions between fetal development and late adolescence may also elevate CVD risk throughout the life course [4-6].

Research over the past two decades has found that childhood trauma and adversity, typically assessed by querying past experience with a variety of physical, emotional, and socioeconomic insults, are important long-term risk factors for adult CVD morbidity $[7,8]$, mortality $[9,10]$, and related cardiometabolic conditions [8] across diverse contexts. Greater childhood adversity has been consistently associated with a range of adult CVDs, including hypertension [6], stroke [11], myocardial infarction [12], and congenital heart disease [13], as well as major CVD risk factors [5]. Early adverse experiences are hypothesized to have durable impacts on CVD risk through the disruption of various psychological, biological, and socioeconomic pathways across child development. For instance, adults with greater self-reported childhood trauma face substantially higher risk for adult psychopathology, such as depression and posttraumatic stress disorder, occurring both independently and comorbid with CVD. These adult psychiatric conditions, along with early life stress, are commonly linked with alterations in stress physiological systems (eg, hypothalamic-pituitary-adrenal axis, sympathetic-adrenal-medullary-axis) that are also involved in the etiology of CVD, such as glucocorticoid dysregulation [14] and heightened systemic inflammation [15].

Despite the alarming rates of CVD burden in sub-Saharan Africa, most studies come from study populations in high-income countries $[16,17]$. In a recent meta-analysis of the global literature on childhood adversity and later-life health, Hughes et al. (2017) describe that "[1]ittle is known about how ACEs predict health outcomes in low-income, high-violence settings, where exposure to adversity is widespread across the life-course." Very little evidence exists on the associations between childhood adversity and adult physical health outcomes, especially CVD risk, in sub-Saharan African contexts [17]. A number of studies from sub-Saharan Africa have shown associations between greater childhood adversity and worse mental health outcomes and self-reported health in adolescence and young adulthood [17-23], but few studies on adult health outcomes exist. To fill this gap in the literature, we estimated the associations between adverse childhood experiences and adult cardiometabolic risk factors and health outcomes in a population-based study of adults living in Mbarara, a rural region of southwestern Uganda.

\section{METHODS}

\section{Study sample}

This study was conducted in the eight villages of Nyakabare Parish, Mbarara, a rural region of southwestern Uganda. The study setting is representative of the larger rural conditions in Mbarara. Nyakabare Parish is geographically isolated, residents mostly engage in subsistence farming, petty trade, and migrant work for labor, and food and water insecurity are prevalent [24,25]. Data were drawn from the second wave of an ongoing, whole-population social network cohort study being conducted in the region [26]. The study includes all adults aged 18 years and above (and emancipated minors aged 16-17 years) who maintain stable primary residence in Nyakabare Parish and who can provide informed consent. Exclusions include people who cannot communicate meaningfully with research staff, for example, because of deafness, mutism, or aphasia; people with behavioral problems thought to represent psychosis, neurological damage, or acute intoxication; and people too cognitively impaired to provide informed consent. The overall response rate was 1630/1795=90.8\%

All participants provided written informed consent before completing all study procedures. Informed consent materials were explained verbally, and research assistants probed for comprehension and answered any questions. Study participants who could not provide a written signature were permitted to indicate consent with a thumbprint. All study procedures were approved by the Mbarara University of Science and Technology and 
Partners Healthcare human studies ethics committees. Per national guidelines, we received clearance to conduct the study from the Uganda National Council for Science and Technology and the Research Secretariat in the Office of the President in Uganda.

\section{Community survey data}

In this study, a modified version of the Adverse Childhood Experiences-International Questionnaire was administered in the second wave (2016-18) to assess experiences of abuse, neglect, and household dysfunction during childhood [27]. The following 16 experiences were queried: 1) verbal abuse, 2) fear of harm, 3) being pushed/grabbed/slapped/hit by an object, 4) scarring from physical abuse, 5) sexually abused, 6) raped, 7) parental divorce, 8) pushed/grabbed/slapped/thrown an object at one's mother, 9) kicked/bit/punched one's mother, 10) threatened mother with weapon, 11) lived with an alcohol/drug abuser, 12) lived with adult with mental illness, 13) incarcerated family member, 14) experienced an entire day without food, 15) went to bed hungry, and 16) went to bed thirsty.

The survey also assessed a series of demographic characteristics, which included an asset inventory that queried the possessions of the following items: radio, lantern, bicycle, television, iron, motorbike, refrigerator, stove, car, and mobile phone; type of toilet facility; materials used to construct the household floors and walls; number of rooms in the home; number of plots of land owned; and number of livestock; and size of the household's rainwater harvesting tank, if any. We created asset index scores using principal component analysis, and households were categorized into quintiles of asset wealth ("wealth quintiles") [28,29].

\section{Community health fair and biomarker data}

During the study, all adults aged at least 18 years of age were invited to attend a multi-sited community-wide health fair [30]. Health fair staff administered study questionnaires, obtained blood samples, and conducted medical screenings. The following cardiometabolic risk factors and health outcomes were assessed: obesity status, defined by conventional waist circumference thresholds ( $\geq 102 \mathrm{~cm}$ for men, $\geq 88 \mathrm{~cm}$ for non-pregnant women) [31]; self-reported history of elevated blood pressure, diabetes, elevated cholesterol, heart attack/heart failure, stroke; hemoglobin Alc (\%); and elevated blood pressure. Alc assessment was done at the time of blood collection using point-of-care Siemens Vantage Alc testing kits (Siemens Medical Solutions USA, Malvern, PA) [32]. Blood pressure was measured in a seated position using automated sphygmomanometers (Omron HEM 705 LP, Omron Healthcare, Inc., Bannockburn, IL), with elevated blood pressure defined as systolic blood pressure $\geq 140 \mathrm{~mm} \mathrm{Hg}$ or diastolic blood pressure $\geq 90 \mathrm{~mm} \mathrm{Hg}$ [33]. Body-mass index (BMI) was assessed by calculating the ratio of weight in kilograms divided by the square of height in meters.

\section{Statistical analysis}

All analyses were conducted using Stata version 15.1 (Stata Corporation, College Station, TX, USA). We examined bivariate relationships to estimate the associations between adult health outcomes and ACEs and the other covariates. We then fitted multiple logistic regression models to the data to estimate the associations between ACEs and cardiometabolic risk factors and health outcomes. With the exception of psychological, household, and social factors that may confound the relationship between ACEs and adult cardiometabolic risk factors and health outcomes, only those variables that were statistically significant at the 0.1 level on bivariate analysis were included in the final multivariable regression models. The following variables were included in the final regression models: age, sex, household asset wealth, educational attainment, marital status, and BMI.

\section{RESULTS}

Data from 545 adults who attended the community health fair and who participated in the community survey were included in this analysis. The mean age was 45.9 years (standard deviation [SD], 15.9), 62\% were women, and most participants did not complete primary school (74.9\%) (Table 1). Adults reported relatively high rates of clinically diagnosed hypertension (30.0\%), and relatively lower levels of diabetes (2.5\%), a past history of heart attack/heart failure (2.3\%), and stroke (2.2\%). Compared to those who participated in the community survey but who did not attend the community health fair, participants who attended the community health fair were more likely to be male, live with a partner, and report a negative history of diabetes.

ACEs were common among study participants: the average number of ACEs was 4.9 out of a possible 16 (Table 2). Living with an adult who used alcohol/drugs was the most commonly reported experience (60\%), followed by experiencing verbal abuse or humiliation (54\%), experiencing physical abuse (51\%), having a family member incarcerated (38\%), and fear of being harmed (38\%). 
Table 1. Socio-demographic and health characteristics of the sample

\begin{tabular}{lcc}
$\begin{array}{l}\text { VARIABLES } \\
\text { Demographics: }\end{array}$ & $\mathbf{N}=\mathbf{5 4 5}$ & $\%$ \\
\hline Gender (\% female) & 337 & 61.8 \\
\hline Age (years): & & \\
\hline $18-25$ & 40 & 7.3 \\
\hline $26-35$ & 122 & 22.4 \\
\hline $36-45$ & 130 & 23.9 \\
\hline $46-55$ & 118 & 21.7 \\
\hline $56+$ & 135 & 24.8 \\
\hline Educational attainment: & & \\
\hline No schooling & 89 & 16.3 \\
\hline Some primary school & 191 & 35.1 \\
\hline Completed primary school & 126 & 23.1 \\
\hline Some secondary school or more & 139 & 25.5 \\
\hline
\end{tabular}

\begin{tabular}{lcc}
$\begin{array}{l}\text { VARIABLES } \\
\text { Living with partner: }\end{array}$ & $\mathbf{N}=\mathbf{5 4 5}$ & $\%$ \\
\hline Yes & 152 & 27.9 \\
\hline No & 393 & 72.1 \\
\hline Self-reported outcomes: & & \\
\hline Diabetes & 14 & 2.6 \\
\hline Heart attack/failure & 31 & 5.7 \\
\hline High cholesterol & 14 & 2.6 \\
\hline Hypertension & 158 & 29.0 \\
\hline Stroke & 11 & 2.0 \\
\hline Measured outcomes: & 14 & \\
\hline Hemoglobin $\geq 6.5 \%$ & 138 & 2.6 \\
\hline High blood pressure & 319 & 25.3 \\
\hline Obesity (waist circumference) & $24.9(5.4) \dagger$ & 58.5 \\
\hline Body-mass index &
\end{tabular}

*The measured outcomes were defined as follows: Hemoglobin Alc assessment was done at the time of blood collection using point-of-care Siemens Vantage Alc testing kits (Siemens Medical Solutions USA, Malvern, PA). Blood pressure was measured in a seated position using automated sphygmomanometers (Omron HEM 705 LP, Omron Healthcare, Inc., Bannockburn, IL), with elevated blood pressure defined as systolic blood pressure $\geq 140 \mathrm{~mm} \mathrm{Hg}$ or diastolic blood pressure $\geq 90 \mathrm{~mm} \mathrm{Hg}$. Waist circumference thresholds for defining obesity were $\geq 102 \mathrm{~cm}$ for men and $\geq 88 \mathrm{~cm}$ for non-pregnant women.

$\uparrow$ These values represent the mean (standard deviation).

Table 2. Frequency of Adverse Childhood Experiences (ACEs)*

\begin{tabular}{lcc} 
ADVERSE CHILDHOOD EXPERIENCES (N = 545) & FREQUENCY & $\%$ \\
\hline Lived with an alcohol/drug abuser & 329 & 0.60 \\
\hline Verbal abuse or humiliation & 292 & 0.54 \\
\hline Pushed, grabbed, slapped, or hit by an object & 277 & 0.51 \\
\hline Incarcerated household family member & 207 & 0.38 \\
\hline Afraid of being harmed & 205 & 0.38 \\
\hline $\begin{array}{l}\text { Pushed, grabbed, slapped, or hit by an object } \\
\text { by mother }\end{array}$ & 178 & 0.33 \\
\hline Lived with an adult with a mental illness & 156 & 0.29 \\
\hline Kicked, bit, or punched mother & 154 & 0.28 \\
\hline Parental separation or divorce & 146 & 0.27 \\
\hline Scarring from physical abuse & 137 & 0.25 \\
\hline Went an entire day without food & 136 & 0.25 \\
\hline Went to bed hungry & 122 & 0.22 \\
\hline Threatened mother with weapon & 116 & 0.21 \\
\hline Went to bed thirsty & 85 & 0.16 \\
\hline Touched sexually & 71 & 0.13 \\
\hline Attempted/forced sex & 55 & 0.10 \\
\hline
\end{tabular}

*Each of the 16 adverse childhood experiences was elicited using a single questionnaire item that enquired about possible exposure to these experiences during the participant's first $18 \mathrm{y}$ of life. For some items, participants were probed about the frequency of the exposure. For the purposes of analysis, all items were converted into binary indicators, with 'any' exposure categorized as 1 and 'no' exposure categorized as 0 .
The unadjusted associations between cumulative number of ACEs and adult cardiometabolic risk factors and health outcomes ranged between odds ratios (OR) of 0.87 (for Alc) and 1.06 (for history of heart attack/heart failure). Table 3 and Table 4 show the estimated associations, using multivariable lo-gistic regression models, between the adult CVD outcomes and ACEs, while Table 5 shows the measured adult CVD outcomes. The cumulative number of ACEs were associated with having a history of heart attack and/or heart failure (adjusted odds ratio $[A O R]=1.11,95 \%$ confidence interval [CI], 0.999-1.234, $P=0.051$ ), but the estimated association was not statistically significant. In the other regression models, the cumulative number of ACEs did not have statistically significant associations with any measures of adult CVD.

\section{DISCUSSION}

In this cross-sectional, population-based study, we find a high prevalence of ACEs among adults living in Mbarara, Uganda. Contrary to our hypotheses, we estimated no statistically significant associations between ACEs and adult CVD outcomes. It is possible that the largely null estimated associations were driven by a relatively small number of events. However, we estimated null associations for the CVD outcomes with both a relatively high (eg, obesity, history of high blood pressure) and a relatively low (eg, positive Alc screen for diabetes; and history of elevated cholesterol, or stroke) number of events. Further, the CVD outcome that was most strongly associated with ACEs (history of heart attack/ heart failure) had a relatively low number of events. Thus we believe it is unlikely that our findings are driven solely by the relatively small number of events.

The null association between ACEs and adult CVD outcomes is inconsistent with the broader literature, which suggests that adults with worse histories of childhood trauma face the greatest risk of developing a variety of CVD conditions [34,35]. Although the majority of these findings are based on data collected in high-income countries, there is not enough evidence from studies in low- and middle-income contexts to make robust conclusions about the extent to which the long-term effects of ACEs on adult CVD can be generalized across these settings. Findings from the nascent literature from low- and middle-income countries are mixed. For example, one large study of Mexican women found that ACEs significantly predicted a suite of CVD risk fac- 
Table 3. Logistic regression models estimating associations between number of ACEs and adult CVD outcomes (diabetes, elevated hemoglobin Alc, heart attack/failure)

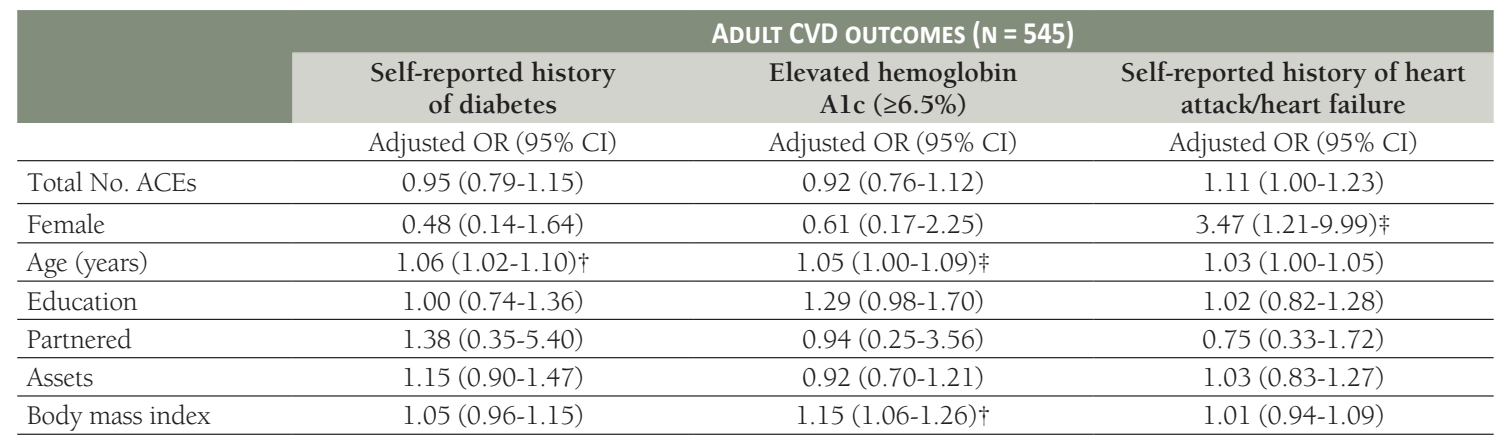

ACEs - adverse childhood experiences, CI - confidence interval, CVD - cardiovascular disease, OR - odds ratio

*Note: Each column represents the estimated regression coefficients from a single multivariable logistic regression model specifying the column header variable as the outcome and the row variables as the covariates. 'Total No. ACEs' represents the total number of adverse childhood experiences out of a maximum of 16. 'Assets' indicates the asset index score derived from a principal components analysis applied to an asset inventory of 19 total different household assets and household characteristics.

$\uparrow P<0.01$

$¥ P<0.05$.

Table 4. Logistic regression models estimating associations between number of ACEs and adult CVD outcomes (elevated cholesterol, stroke, hypertension)*

\begin{tabular}{lccc} 
& $\begin{array}{c}\text { Self-reported history } \\
\text { of elevated cholesterol } \\
\text { Adjusted OR (95\% CI) }\end{array}$ & $\begin{array}{c}\text { ADULT CVD outcomes ( } \mathbf{N}=5 \text { 45) } \\
\text { Self-reported history } \\
\text { of stroke }\end{array}$ & $\begin{array}{c}\text { Self-reported history } \\
\text { of hypertension } \\
\text { Adjusted OR (95\% CI) }\end{array}$ \\
\hline Total number of ACEs & $1.10(0.92-1.31)$ & $1.02(0.85-1.21)$ & $0.96(0.91-1.02)$ \\
\hline Female & $1.06(0.20-5.78)$ & $1.58(0.35-7.06)$ & $0.75(0.49-1.20)$ \\
\hline Age (years) & $1.05(1.01-1.10) \dagger$ & $1.01(0.97-1.06)$ & $1.05(1.03-1.06) \dagger$ \\
\hline Education & $1.40(1.01-1.93) \dagger$ & $1.07(0.75-1.51)$ & $0.89(0.79-1.00) \ddagger$ \\
\hline Partnered & $0.86(0.22-3.38)$ & $1.26(0.75-1.51)$ & $0.89(0.56-1.41)$ \\
\hline Assets & $0.66(0.41-1.05)$ & $0.81(0.48-1.36)$ & $1.08(0.96-1.22)$ \\
\hline Body mass index & $1.28(1.16-1.42) \dagger$ & $1.03(0.91-1.17)$ & $1.03(0.99-1.08)$ \\
\hline
\end{tabular}

ACEs - adverse childhood experiences, CI - confidence interval, CVD - cardiovascular disease, OR - odds ratio

*Note: Each column represents the estimated regression coefficients from a single multivariable logistic regression model specifying the column header variable as the outcome and the row variables as the covariates. 'Total No. ACEs' represents the total number of adverse childhood experiences out of a maximum of 16. 'Assets' indicates the asset index score derived from a principal components analysis applied to an asset inventory of 19 total different household assets and household characteristics.

$\uparrow P<0.001$

$\ddagger P<0.05$.

Table 5. Logistic regression models estimating associations between number of ACEs and adult CVD outcomes (elevated blood pressure, obesity by waist circumference)*

\begin{tabular}{|c|c|c|}
\hline & \multicolumn{2}{|c|}{ ADULT CVD OUTCOMES (N = 545) } \\
\hline & Elevated blood pressure (>140/90 $\mathrm{mm} \mathrm{Hg}$ ) & Obesity by waist circumference \\
\hline & Adjusted OR $(95 \%$ CI $)$ & Adjusted OR (95\% CI) \\
\hline Total No. ACEs & $0.95(0.89-1.02)$ & $0.99(0.93-1.05)$ \\
\hline Female & $0.74(0.46-1.19)$ & $5.07(3.05-8.43) \dagger$ \\
\hline Age (years) & $1.05(1.03-1.06) \dagger$ & $1.02(1.00-1.04) \ddagger$ \\
\hline Education & $0.93(0.83-1.05)$ & $0.95(0.84-1.07)$ \\
\hline Partnered & $1.20(0.73-1.95)$ & $1.19(0.73-1.95)$ \\
\hline Assets & $1.07(0.94-1.21)$ & $1.02(0.88-1.17)$ \\
\hline Body mass index & $1.03(0.99-1.08)$ & $1.22(1.15-1.29) \dagger$ \\
\hline
\end{tabular}

ACEs - adverse childhood experiences, CI - confidence interval, CVD - cardiovascular disease, OR - odds ratio

* Note: Each column represents the estimated regression coefficients from a single multivariable logistic regression model specifying the column header variable as the outcome and the row variables as the covariates. 'Total No. ACEs' represents the total number of adverse childhood experiences out of a maximum of 16. 'Assets' indicates the asset index score derived from a principal components analysis applied to an asset inventory of 19 total different household assets and household characteristics.

$\uparrow P<0.001$

$\$ P<0.05$. 
tors, such as hypertension, diabetes, and high cholesterol, during adulthood [7]. Conversely, another study of adults in metropolitan Manila, Philippines reported null associations between ACEs and adult CVD conditions like diabetes and stroke, but significant associations between ACEs and future risk for hypertension and ischemic heart disease [36]. The limited number of studies that report null associations between ACEs and adult cardiometabolic risk factors and cardiovascular disease outcomes may also be driven by publication bias, with those reporting statistically significant associations more likely to be published.

A number of reasons may explain the null relationships between ACEs and adverse cardiometabolic and cardiovascular outcomes in this sample. First, our models may have excluded the role of protective factors that may buffer adults from the long-term cardiometabolic and cardiovascular effects of early trauma exposure, such as the positive effects of psychological resources [37], social support [38] and cultural integration [39]. Second, the psychological and physiological impacts of certain forms of childhood trauma do not necessarily have a deterministic effect on future elevated disease risk or adversely affect the stress physiological pathways understood to underlie these long-term effects. For example, previously published studies have found null associations between early life stress and adult stress physiology outcomes, including autonomic regulation $[40,41]$ and hypothalamic-pituitary-adrenal axis function [41,42]. Given the increased prevalence and burden of both ACEs and CVDs in low- and middle-income contexts, further research studies from these settings are needed to elucidate the possible long-term effects of ACEs on adult CVD risk.

While our study design is characterized by many strengths, including the fairly comprehensive ACEs assessment, extensive sampling of an understudied setting (relative to the rest of the ACEs and global cardiovascular health literature), and comprehensive screening of various cardiometabolic and cardiovascular health outcomes, this analysis includes a number of limitations. First, retrospective reports of ACEs may be limited by certain cognitive biases (eg, recency effect, availability heuristic), memory loss, and/or current emotional states [4345]. Self-reported history of CVD outcomes may be similarly limited. However, correlated errors in self-report (of both ACEs and CVD outcomes) would be expected to bias our estimated associations away from the null rather than toward the null. For self-report measurement errors to bias our estimated associations toward the null, the cognitive biases, memory loss, and/or current emotional states would need to bias the exposure away from the null and bias the outcome toward the null (or vice versa). Second, the adaptation of the international ACEs survey tool may have excluded common and contextually relevant forms of child adversity, leading to a possible underreporting of childhood trauma and potential source of measurement error [46]. Finally, we did not directly assess CVD markers with the exception of hemoglobin Alc, waist circumference, and blood pressure. The use of self-reported history for most of our outcome measures may conceal possible long-term adult cardiovascular effects of ACEs due to the lack of resolution in our categorical outcome measures.

Nevertheless, this study contributes to the nascent literature on the long-term, adult cardiovascular effects of adverse childhood experiences in low- and middle-income contexts. We find that adverse childhood experiences are not associated with a suite of adult cardiometabolic risk factors and health outcomes in this sample of rural Ugandan adults. Further research in this sample is necessary to identify the pathways that may motivate the null relationship and possibly protect against adverse cardiovascular health outcomes.

Acknowledgements: We thank the HopeNet cohort study participants, without whom this research would not be possi-
ble. We also thank members of the HopeNet study team for research assistance. In addition to the named study authors,
HopeNet Study team members who contributed to data collection and/or study administration during all or any part
of the study were as follows: Phiona Ahereza, Owen Alleluya, Dickson Beinomugisha, Bridget Burns, Patrick Gumisiri-
za, Mercy Juliet, Clare Kamagara, Justus Kananura, Viola Kyokunda, Godfrey Massette, Patrick Lukwago Muleke, Rhina
Mushagara, Rumbidzai Mushavi, Elijah Musinguzi, Immaculate Ninsiima, Moran Owembabazi, Mellon Tayebwa, Ezra
Turinanwe, Julius Turyasingura, and Dagmar Vořechovská. We also thank Roger Hofmann of West Portal Software Cor-
poration (San Francisco, CA, USA), for developing and customizing the CASIC Builder software program used for survey
administration. No endorsement of manuscript contents or conclusions should be inferred from these acknowledgments.
Funding: This work was supported by Friends for a Healthy Uganda and US National Institutes of Health (NIH)
[R01MH113494 and R01MH125667]. AWK is supported by a US National Science Foundation Graduate Research Fel-
lowship and the Fogarty International Center and National Institute of Mental Health [NIH D43TW010543]. The content
is solely the responsibility of the authors and does not necessarily represent the official views of the NIH.
Authorship contributions: AWK conceptualized the paper, conducted the analysis, and wrote the manuscript. CB, CMN,
ENS, JMP, PA, AK, EBN, and MJS collected the data. BK, DRB, MJS, and ACT designed the study and secured funding.
ACT supervised the analysis and writing of the manuscript. All authors contributed to revising manuscript for important
intellectual content.
Competing interests: The authors have completed the ICMJE Uniform Conflict of Interest form (available upon request
from the corresponding author) and declare no conflicts of interest.


1 GBD 2017 Causes of Death Collaborators. Global, regional, and national age-sex-specific mortality for 282 causes of death in 195 countries and territories, 1980-2017: a systematic analysis for the Global Burden of Disease Study 2017. Lancet. 2018;392:1736-88. Medline:30496103 doi:10.1016/S0140-6736(18)32203-7

2 Yuyun MF, Sliwa K, Kengne AP, Mocumbi AO, Bukhman G. Cardiovascular Diseases in Sub-Saharan Africa Compared to High-Income Countries: An Epidemiological Perspective. Glob Heart. 2020;15:15. Medline:32489788 doi:10.5334/gh.403

3 Amegah AK. Tackling the Growing Burden of Cardiovascular Diseases in Sub-Saharan Africa. Circulation. 2018;138:2449-51. Medline:30571350 doi:10.1161/CIRCULATIONAHA.118.037367

4 Kuzawa CW, Hallal PC, Adair L, Bhargava SK, Fall CH, Lee N, et al. Birth weight, postnatal weight gain, and adult body composition in five low and middle income countries. Am J Hum Biol. 2012;24:5-13. Medline:22121058 doi:10.1002/ajhb.21227

5 Su S, Jimenez MP, Roberts CT, Loucks EB. The role of adverse childhood experiences in cardiovascular disease risk: a review with emphasis on plausible mechanisms. Curr Cardiol Rep. 2015;17:88. Medline:26289252 doi:10.1007/s11886-015-0645-1

6 Obi IE, McPherson KC, Pollock JS. Childhood adversity and mechanistic links to hypertension risk in adulthood. Br J Pharmacol. 2019;176:1932-50. Medline:30656638 doi:10.1111/bph.14576

7 Flores-Torres MH, Comerford E, Signorello L, Grodstein F, Lopez-Ridaura R, de Castro F, et al. Impact of adverse childhood experiences on cardiovascular disease risk factors in adulthood among Mexican women. Child Abuse Negl. 2020;99:104175. Medline:31710961 doi:10.1016/j.chiabu.2019.104175

8 Salas J, van den Berk-Clark C, Skiold-Hanlin S, Schneider FD, Scherrer JF. Adverse childhood experiences, depression, and cardiometabolic disease in a nationally representative sample. J Psychosom Res. 2019;127:109842. Medline:31671348 doi:10.1016/j.jpsychores.2019.109842

9 Bellis MA, Hughes K, Leckenby N, Hardcastle KA, Perkins C, Lowey H. Measuring mortality and the burden of adult disease associated with adverse childhood experiences in England: a national survey. J Public Health (Oxf). 2015;37:445-54. Medline:25174044 doi:10.1093/pubmed/fdu065

10 Pierce JB, Kershaw KN, Kiefe CI, Jacobs DR Jr, Sidney S, Merkin SS, et al. Association of Childhood Psychosocial Environment With 30-Year Cardiovascular Disease Incidence and Mortality in Middle Age. J Am Heart Assoc. 2020;9:e015326. Medline:32342717 doi:10.1161/JAHA.119.015326

11 Nandi A, Glymour MM, Kawachi I, VanderWeele TJ. Using marginal structural models to estimate the direct effect of adverse childhood social conditions on onset of heart disease, diabetes, and stroke. Epidemiology. 2012;23:223-32. Medline:22317806 doi:10.1097/EDE.0b013e31824570bd

12 Monnat SM, Chandler RF. Long Term Physical Health Consequences of Adverse Childhood Experiences. Sociol Q. 2015;56:72352. Medline:26500379 doi:10.1111/tsq.12107

13 Felitti VJ, Anda RF, Nordenberg D, Williamson DF, Spitz AM, Edwards V, et al. REPRINT OF: Relationship of Childhood Abuse and Household Dysfunction to Many of the Leading Causes of Death in Adults: The Adverse Childhood Experiences (ACE) Study. Am J Prev Med. 2019;56:774-86. Medline:31104722 doi:10.1016/j.amepre.2019.04.001

14 Juruena MF, Cleare AJ, Young AH. The role of early life stress in HPA axis and depression. Understanding depression. New York, NY: Springer; 2018.

15 Osimo EF, Baxter LJ, Lewis G, Jones PB, Khandaker GM. Prevalence of low-grade inflammation in depression: a systematic review and meta-analysis of CRP levels. Psychol Med. 2019;49:1958-70. Medline:31258105 doi:10.1017/S0033291719001454

16 Hughes K, Bellis MA, Hardcastle KA, Sethi D, Butchart A, Mikton C, et al. The effect of multiple adverse childhood experiences on health: a systematic review and meta-analysis. Lancet Public Health. 2017;2:e356-66. Medline:29253477 doi:10.1016/ S2468-2667(17)30118-4

17 Kidman R, Piccolo LR, Kohler HP. Adverse Childhood Experiences: Prevalence and Association With Adolescent Health in Malawi. Am J Prev Med. 2020;58:285-93. Medline:31810632 doi:10.1016/j.amepre.2019.08.028

18 Cluver L, Orkin M, Boyes ME, Sherr L. Child and Adolescent Suicide Attempts, Suicidal Behavior, and Adverse Childhood Experiences in South Africa: A Prospective Study. J Adolesc Health. 2015;57:52-9. Medline:25936843 doi:10.1016/j. jadohealth.2015.03.001

19 Jewkes RK, Dunkle K, Nduna M, Jama PN, Puren A. Associations between childhood adversity and depression, substance abuse and HIV and HSV2 incident infections in rural South African youth. Child Abuse Negl. 2010;34:833-41. Medline:20943270 doi:10.1016/j.chiabu.2010.05.002

20 Lawal OT, Abdulmalik JO. Adverse Childhood Experiences and Psychosocial Wellbeing among Pre-clinical Medical Students in a Nigerian University. African Journal of Biomedical Research. 2020;23(Special Edition 1):47-52.

21 Manyema M, Norris SA, Richter LM. Stress begets stress: the association of adverse childhood experiences with psychological distress in the presence of adult life stress. BMC Public Health. 2018;18:835. Medline:29976168 doi:10.1186/s12889-0185767-0

22 Oladeji BD, Makanjuola VA, Gureje O. Family-related adverse childhood experiences as risk factors for psychiatric disorders in Nigeria. Br J Psychiatry. 2010;196:186-91. Medline:20194539 doi:10.1192/bjp.bp.109.063677

23 Salawu M, Owoaje E. Prevalence and Predictors of Adverse Childhood Experiences among Youths in Rural communities of Oyo State, South-west, Nigeria. Journal of Community Medicine and Primary Health Care. 2020;32:27-41. doi:10.4314/jcmphc.v32i2.3

24 Mushavi RC, Burns BFO, Kakuhikire B, Owembabazi M, Vorechovska D, McDonough AQ, et al. "When you have no water, it means you have no peace": A mixed-methods, whole-population study of water insecurity and depression in rural Uganda. Soc Sci Med. 2020;245:112561. Medline:31790879 doi:10.1016/j.socscimed.2019.112561

25 Tsai AC, Bangsberg DR, Frongillo EA, Hunt PW, Muzoora C, Martin JN, et al. Food insecurity, depression and the modifying role of social support among people living with HIV/AIDS in rural Uganda. Soc Sci Med. 2012;74:2012-9. Medline:22513248 doi:10.1016/j.socscimed.2012.02.033 
26 Takada S, Nyakato V, Nishi A, O’Malley AJ, Kakuhikire B, Perkins JM, et al. The social network context of HIV stigma: Population-based, sociocentric network study in rural Uganda. Soc Sci Med. 2019;233:229-36. Medline:31229909 doi:10.1016/j. socscimed.2019.05.012

27 Satinsky EN, Kakuhikire B, Baguma C, Rasmussen JD, Ashaba S, Cooper-Vince CE, et al. Adverse childhood experiences, adult depression, and suicidal ideation in rural Uganda: a cross-sectional, population-based study. PLoS Med. In press. Medline:33979329

28 Smith ML, Kakuhikire B, Baguma C, Rasmussen JD, Bangsberg DR, Tsai AC. Do household asset wealth measurements depend on who is surveyed? Asset reporting concordance within multi-adult households in rural Uganda. J Glob Health. 2020;10:010412. Medline:32373331

29 Filmer D, Pritchett LH. Estimating wealth effects without expenditure data-or tears: an application to educational enrollments in states of India. Demography. 2001;38:115-32. Medline:11227840

30 North CM, Kakuhikire B, Vorechovska D, Hausammann-Kigozi S, McDonough AQ, Downey J, et al. Prevalence and correlates of chronic obstructive pulmonary disease and chronic respiratory symptoms in rural southwestern Uganda: a cross-sectional, population-based study. J Glob Health. 2019;9:010434. Medline:31217961 doi:10.7189/jogh.09.010434

31 Grundy SM, Cleeman JI, Daniels SR, Donato KA, Eckel RH, Franklin BA, et al. Diagnosis and management of the metabolic syndrome: an American Heart Association/National Heart, Lung, and Blood Institute scientific statement: Executive Summary. Crit Pathw Cardiol. 2005;4:198-203. Medline:18340209 doi:10.1097/00132577-200512000-00018

32 Magodoro IM, Feng M, North CM, Vorechovska D, Kraemer JD, Kakuhikire B, et al. Female sex and cardiovascular disease risk in rural Uganda: a cross-sectional, population-based study. BMC Cardiovasc Disord. 2019;19:96. Medline:31023227 doi:10.1186/s12872-019-1072-9

33 Magodoro IM, Albano AJ, Muthalaly R, Koplan B, North CM, Vorechovska D, et al. Population Prevalence and Correlates of Prolonged QT Interval: Cross-Sectional, Population-Based Study From Rural Uganda. Glob Heart. 2019;14:17-25 e4. Medline:30584028 doi:10.1016/j.gheart.2018.11.002

34 Basu A, McLaughlin KA, Misra S, Koenen KC. Childhood Maltreatment and Health Impact: The Examples of Cardiovascular Disease and Type 2 Diabetes Mellitus in Adults. Clin Psychol (New York). 2017;24:125-39. Medline:28867878 doi:10.1111/ cpsp. 12191

35 Danese A, Tan M. Childhood maltreatment and obesity: systematic review and meta-analysis. Mol Psychiatry. 2014;19:54454. Medline:23689533 doi:10.1038/mp.2013.54

36 Ramiro LS, Madrid BJ, Brown DW. Adverse childhood experiences (ACE) and health-risk behaviors among adults in a developing country setting. Child Abuse Negl. 2010;34:842-55. Medline:20888640 doi:10.1016/j.chiabu.2010.02.012

37 Cohrdes C, Mauz E. Self-efficacy and emotional stability buffer negative effects of adverse childhood experiences on young adult health-related quality of life. J Adolesc Health. 2020;67:93-100. Medline:32192828 doi:10.1016/j.jadohealth.2020.01.005

38 Godoy LC, Frankfurter C, Cooper M, Lay C, Maunder R, Farkouh ME. Association of Adverse Childhood Experiences With Cardiovascular Disease Later in Life: A Review. JAMA Cardiol. 2021;6:228-35. Medline:33263716 doi:10.1001/jamacardio.2020.6050

39 Brockie TN, Elm JH, Walls ML. Examining protective and buffering associations between sociocultural factors and adverse childhood experiences among American Indian adults with type 2 diabetes: a quantitative, community-based participatory research approach. BMJ Open. 2018;8:e022265. Medline:30232110 doi:10.1136/bmjopen-2018-022265

40 Bakema MJ, van Zuiden M, Collard D, Zantvoord JB, de Rooij SR, Elsenburg LK, et al. Associations Between Child Maltreatment, Autonomic Regulation, and Adverse Cardiovascular Outcome in an Urban Population: The HELIUS Study. Front Psychiatry. 2020;11:69. Medline:32256391 doi:10.3389/fpsyt.2020.00069

41 van Ockenburg SL, Tak LM, Bakker SJ, Gans RO, de Jonge P, Rosmalen JG. Effects of adverse life events on heart rate variability, cortisol, and C-reactive protein. Acta Psychiatr Scand. 2015;131:40-50. Medline:24833194 doi:10.1111/acps.12286

42 Kim AW, Adam EK, Bechayda SA, Kuzawa CW. Early life stress and HPA axis function independently predict adult depressive symptoms in metropolitan Cebu, Philippines. Am J Phys Anthropol. 2020;173:448-62. Medline:32744374 doi:10.1002/ ajpa. 24105

43 Entringer S, Buss C, Wadhwa PD. Prenatal stress, development, health and disease risk: A psychobiological perspective-2015 Curt Richter Award Paper. Psychoneuroendocrinology. 2015;62:366-75. Medline:26372770 doi:10.1016/j.psyneuen.2015.08.019

44 Naicker SN, Norris SA, Mabaso M, Richter LM. An analysis of retrospective and repeat prospective reports of adverse childhood experiences from the South African Birth to Twenty Plus cohort. PLoS One. 2017;12:e0181522. Medline:28746343 doi:10.1371/journal.pone.0181522

45 Wadhwa PD, Sandman CA, Porto M, Dunkel-Schetter C, Garite TJ. The association between prenatal stress and infant birth weight and gestational age at birth: a prospective investigation. Am J Obstet Gynecol. 1993;169:858-65. Medline:8238139 doi:10.1016/0002-9378(93)90016-C

46 Schmidt MR, Narayan AJ, Atzl VM, Rivera LM, Lieberman AF. Childhood maltreatment on the Adverse Childhood Experiences (ACEs) Scale versus the Childhood Trauma Questionnaire (CTQ) in a perinatal sample. J Aggress Maltreat Trauma. 2020;29:3856. doi:10.1080/10926771.2018.1524806 